\title{
Application Analysis on Internal Rate of Return Rule for Investment Decision
}

\author{
Liyang Jiang ${ }^{1, a}$ \\ ${ }^{1}$ School of Business management, Tonghua Normal University, Tonghua 134002, China. \\ adbcy9999@163.com
}

\begin{abstract}
Keywords: net present value rule, capital budgeting decisions, internal rate of return, cash,
\end{abstract} investment decision.

\begin{abstract}
The net present value (NPV) rule is not the only criterion available to evaluate a capital investment proposal. You may be familiar with the payback period, the internal rate of return, or another criterion. This paper examines and explains how to apply to the NPV rule: the internal-rate-of-return (IRR) rule, the criteria used by a large sample of companies when making capital budgeting decisions, with the IRR rules being the most popular and the average accounting return and PI rules being the least popular. We analyze whether the internal-rate-of-return (IRR) rule satisfy the conditions of a good investment decision rule. Recall that a good investment decision rule must take into account the timing of a project's expected cash flows and the project's risk. In addition, it should select projects that increase the market value of the firm's equity. In our analysis of the alternative rules, we identify a number of cases in which the methods lead to a decision that contradicts the NPV rule. We explain why these conflicts occur and why some firms still use some of these techniques to screen investment proposals. We use the projects to illustrate how the alternatives to the NPV rule are usually applied in making investment decisions and compare their performance with that of the NPV rule. .
\end{abstract}

\section{Introduction}

The steps involved in applying the NPV [1-3] rule to evaluate an investment proposal are summarized in this paper. Tow inputs are required to calculate a project's NPV: (1) the expected cash-flow stream that the project will generate over its useful life and (2) the appropriate cost of capital that reflects the risk of the expected cash-flows. The cost of capital is the rate at which the project's future cash flows need to be discounted to compare their present value with the investment cost.

That a good investment decision rule must take into account the timing of a project's expected cash flows and the project's risk. In addition, it should select projects that increase the market value of the firm's equity A project's payback period is the number of periods (usually measured in years) required for the sum of the project's expected cash flows to equal its initial cash outlay. In other words, the payback period is the time it takes for a firm to recover its initial investment. Consider investment A, whose characteristics are reported in Table 1 and whose expected and cumulative cash flows are shown in Table 2. The investment's payback period is the length of time it takes for the firm to get back its initial cash outlay of $\$ 1$ million.

Table 1 EXPECTED CASH-FLOW STREAMS, COST OF CAPITAL, AND NET PRESENT VALUES OF ALTERNATIVE INVESTMENT PROPOSALS (ALL INVESTMENTS ARE FIVE YEARS LONG AND REQUIRE AN INITIAL CASH OUTLAY OF \$1 MILLION)

\begin{tabular}{|c|c|c|}
\hline End-of-Year & Investment E & Investment $\mathrm{F}$ \\
\hline 1 & $\$ 325,000$ & $\$ 325,000$ \\
\hline 2 & 325,000 & 325,000 \\
\hline 3 & 325,000 & 325,000 \\
\hline 4 & 325,000 & 325,000 \\
\hline 5 & 325,000 & 925,000 \\
\hline Total cash flows & $\$ 1,625,000$ & $\$ 2,275,000$ \\
\hline Cost of capital & $10 \%$ & $10 \%$ \\
\hline NPV & $\$ 232,006$ & $\$ 635,605$ \\
\hline
\end{tabular}


Table 2 EXPECTED CASH-FLOW S FROM Table 1

\begin{tabular}{|c|c|c|}
\hline End-of-Year & Expected Cash Flows & Cumulative Cash Flows \\
\hline 1 & $\$ 600,000$ & $\$ 600,000$ \\
\hline 2 & $\$ 300,000$ & $\$ 900,000$ \\
\hline 3 & $\$ 100,000$ & $\$ 1000,000$ \\
\hline 4 & $\$ 200,000$ & $\$ 1200,000$ \\
\hline 5 & $\$ 300,000$ & $\$ 1500,000$ \\
\hline
\end{tabular}

A project's internal rate of return (IRR) is the discount rate that makes the NPV [1-3] of the project equal to zero. For example, to compute the IRR of investment $E$ and F, we set NPV (E and F) equal to zero and find the discount rate that satisfies this condition. That rate is the investment's IRR:

Unfortunately, there is no simple way to compute the IRR of a cash-flow stream except for the trivial case in which the project is a one-period investment or an annuity.

All that is needed to calculate the IRR of an investment is the sequence of cash flows the investment is expected to generate. In effect, an investment's IRR summarizes its expected cash-flow stream with a single rate of return. The rate is called internal because it considers only the expected cash flows related to the investment and does not depend on rates that can be earned on alternative investments.

\section{The IRR Rule}

Consider investment A. Its IRR is 19.05 percent, and its opportunity cost of capital [4-5] is 10 percent. Recall that investment A's opportunity cost of capital is the highest return a firm can get on an alternative investment with the same risk as A. Should the firm accept investment A? Yes, because the project's IRR (19.05 percent) is greater than the highest return the firm can get on another investment with the same risk (the 10 percent opportunity cost of capital).

Table 3 IRR FOR THE SIX INVESTMENTS IN Table 1.

\begin{tabular}{|l|l|l|}
\hline Investment & $\mathrm{E}$ & $\mathrm{F}$ \\
\hline Internal rate of return & 18.7 & 28.5 \\
& 2 & 2 \\
& $\%$ & $\%$ \\
\hline
\end{tabular}

According to the internal rate of return rule, an investment should be accepted if its IRR is higher than its cost of capital and should be rejected if its IRR is lower. If the investment's IRR is equal to the cost of capital, the firm should be indifferent about accepting or rejecting the project. A project's IRR can be interpreted as a measure of the profitability of its expected cash flow before considering the project's cost of capital. Thus, if a project's IRR is lower than its cost of capital, the project does not earn its cost of capital and should be rejected. If it is higher, the project earns more than its cost of capital and should be accepted. When used in comparison with the IRR, the investment's opportunity cost of capital is usually referred to as the hurdle rate, the minimum required rate of return, or, simply, the investment's required return. In other words, if a project's IRR is lower than its required return, it should be rejected; if it is higher, it should be accepted.

\section{Dose the IRR Rule maximize the firm's equity value?}

A project's IRR is determined by setting its NPV equal to zero, so we would expect a project's NPV to be related to its IRR. To illustrate, we compute the NPV of investment $E$ for various discount rates, as shown in Table 4.

Table 4 NET PRESENT VALUE OF INVESTMENT E FOR VARIOUS DISCOUNT RATES.

\begin{tabular}{|l|l|l|l|}
\hline Discount Rate & $0 \%$ & $5 \%$ & $10 \%$ \\
\hline NPV(E) & $\$ 625,000$ & $\$ 407,080$ & $\$ 232,006$ \\
\hline $15 \%$ & $20 \%$ & $25 \%$ & $30 \%$ \\
\hline$\$ 89,450$ & $-\$ 28,05$ & $-\$ 125,98$ & $-\$ 208,44$ \\
& 0 & 4 & 0 \\
\hline
\end{tabular}

From the figures in Table 4, we can draw a graph that shows the changes in NPV (E) as the discount rate varies. The graph, known as the project's NPV profile, is shown in Fig.1 NPV (E) is on 
the vertical axis and the discount rate is on the horizontal axis. The graph shows an inverse relationship between NPV (E) and the discount rate. As the discount rate increases, NPV (E) decreases because its expected cash flows are discounted at increasingly higher rates. The NPV curve intersects the horizontal axis at the point at which NPV (E) is equal to zero. At this point, the discount rate used to calculate the NPV of investment $E$ must be equal to the IRR of investment $E$ because the IRR is the discount rate at which the NPV is equal to zero. This discount rate is 18.72 percent (see Fig.1).

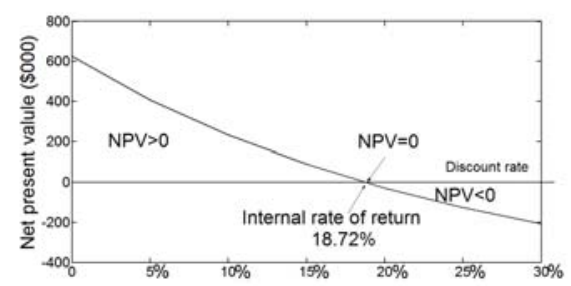

Fig. 1 The NPV Profile of Investment E.

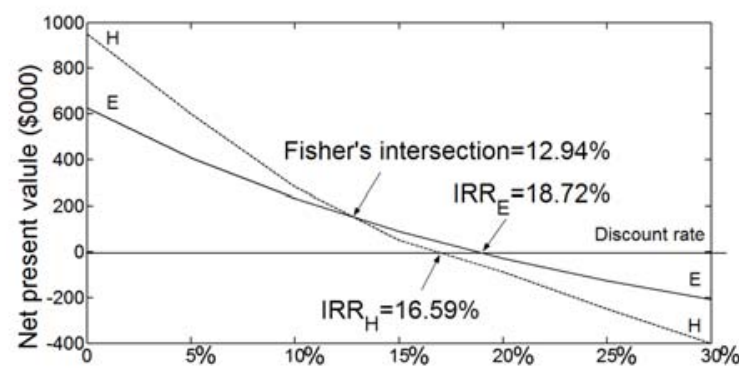

Fig. 2 The NPV Profile of Investment E AND H.

According to the IRR rule, investment $\mathrm{E}$ should be accepted if its cost of capital is lower than its IRR of 18.72 percent and should be rejected if its cost of capital is higher. The graph indicates that for discount rates (or costs of capital) lower than 18.72 percent, the project's NPV is positive, and for discount rates higher than 18.72 percent, the project's NPV is negative. In other words, the graph indicates that when the NPV is positive, the IRR is higher than the cost of capital, and when it is negative, the IRR is lower than the cost of capital. The two rules are thus equivalent. And because the NPV rule is consistent with the maximization of the firm's equity value, so is the IRR rule.

\section{The IRR Rule may be unreliable}

The IRR rule may sometimes provide the incorrect investment decision [6-7] when (1) the firm is reviewing two mutually exclusive investments (the firm cannot invest in both; if it accepts one, it must reject the other), and (2) the project's cash-flow stream changes signs more than once (the sequence of future cash flows contains at least one negative cash flow after a positive one).

\section{The case of mutually exclusive investments}

When two projects are mutually exclusive, the IRR rule and the NPV rule [8] may, under certain circumstances, select different investment proposals. They have the same useful life (five years), the same initial cash outlay ( $\$ 1$ million), and the same cost of capital (10 percent). Investment $\mathrm{E}$ has an IRR of 18.72 percent, and investment $H$ has an IRR of 16.59 percent (see Fig.2). Both investments have an IRR that exceeds the cost of capital of 10 percent, so they should both be accepted according to the IRR rule. However, the investments are mutually exclusive, so the firm can accept only one. Which should it select? Intuition suggests the selection of investment E because it has a higher IRR than investment $\mathrm{H}$. Unfortunately, intuition does not always lead to the correct decision. According to the NPV rule, investment $\mathrm{H}$ is preferable to investment $\mathrm{E}$ : at a cost of capital of 10 percent, the NPV of investment $H$ is $\$ 282,519$, whereas that of investment $E$ is only $\$ 232,006$. The NPV profiles of investments $\mathrm{E}$ and $\mathrm{H}$ in Exhibit 7.15 show why the IRR and NPV rules disagree. The graph indicates that both the NPV and IRR rules favor investment E when the discount rate is higher than 12.94 percent (the rate at which the two NPV curves intersect) and lower than 18.72 percent. For rates above 18.72 percent, the two projects should be rejected; both have a negative NPV and a discount rate higher than the IRR. For rates lower than 12.94 percent, the NPV rule favors investment H, but the IRR rule still favors investment $\mathrm{E}$ (it has a higher IRR than $\mathrm{H}$ ). This situation usually arises when the cash-flow patterns of two mutually exclusive investments differ widely, as in the case of investments $\mathrm{E}$ and H. Investment E's cash flows are evenly distributed during the project's life, 
whereas those of $\mathrm{H}$ are concentrated in the last year of the project's life. At high discount rates, the discounting effect (the "shrinking" of cash flows resulting from discounting) on distant cash flows is more pronounced than when the rate is low. As a consequence, when the discount rate increases, the NPV of the investment with cash flows concentrated at the end of the project's life (such as investment $\mathrm{H}$ ) decreases more rapidly than the NPV of the investment whose cash flows arise earlier (such as investment E). The two projects have the same NPV at the point at which their NPV curves intersect. After that point, the NPV ranking of the two projects changes. With a cost of capital of 10 percent, project $\mathrm{H}$ is the better investment because its NPV is larger than that of project E, thus creating more value to the firm's owners. Because the IRR approach would lead to the opposite choice, it would also have the opposite effect. In general, when a firm wants to rank projects according to their contribution to the value of the firm's equity, it should use the NPV rule rather than the IRR rule.

\section{The case of investments with some negative future cash flows}

The IRR rule may be unreliable when a project's stream of expected cash flows includes negative cash flows. Negative cash flows can occur when an investment requires the construction of several facilities that are built at different times in the future. During the year when a new unit is built, the cash flow generated by the previously installed unit might not be large enough to cover the cost of the new one. The result is that the project's total cash flow for that year becomes negative. A project can also have a negative future cash flow if the project's termination requires a major capital expenditure, such as for a strip-mining project. Closing the mine and restoring the area's landscape at the end of the project's useful life may make the project's terminal cash flow negative. When negative cash flows occur, a project may have more than one IRR or none at all. We illustrate this phenomenon with a two-year project that has a cost of capital of 20 percent and the pattern of expected cash flows shown.

The project [9-10] has an IRR of 5 percent and an IRR of 40 percent. (If you check this, you will find that the project's NPV is zero at both 5 percent and 40 percent.) If the project has a cost of capital of 20 percent, it should be rejected if its IRR is 5 percent and accepted if it's IRR is 40 percent. The choice is not obvious. What should the firm's managers do in this case? They should ignore the IRR rule and use the NPV rule instead. At a cost of capital of 20 percent, the project has a positive NPV of $\$ 20,833$ and should be undertaken.

\section{Why do managers usually prefer the IRR Rule to the NPV Rule?}

Despite its shortcomings, the IRR rule is popular among managers. One reason may be that the calculation of a project's IRR requires a single input, the cash-flow stream that the project is expected to generate. An estimate of the project's cost of capital is not necessary, whereas the calculation of a project's NPV requires estimates of both the expected cash-flow stream and the cost of capital. However, the application of the IRR rule requires both inputs. To decide whether to invest, managers must compare the project's IRR to its cost of capital. Thus, even though the IRR can be computed without knowing the project's cost of capital, the cost of capital is still needed to decide whether to undertake the project. If both methods require the same inputs to select projects, what is the advantage of using the IRR rule? The advantage may be that it is easier to estimate a project's IRR than its NPV when the project's cost of capital is uncertain (the computation of the IRR does not require knowing the cost of capital). Then, the decision whether to accept or reject the project is made after an appropriate required return is determined.

Our advice: a project's NPV can be estimated with the same information required to apply the IRR rule, so you should compute both. When both rules lead to the same recommendation, mention the project's IRR instead of its NPV. When the outcome of your analysis indicates a conflict between the two methods, you should trust the NPV rule. 


\section{Summary}

Our analysis of the alternatives to the net present value (NPV) rule has shown that the NPV rule is the best criterion for selecting desirable investment proposals (projects that are expected to raise the market value of a firm's equity and, thereby, increase the wealth of the firm's owners). This conclusion does not imply that the alternative capital budgeting techniques presented in this paper should be discarded. A project's profitability index, internal rate of return, payback period, and average accounting return may provide useful information to managers and are often easier to interpret and communicate than the NPV. As Table 1shows, companies rarely rely on a single method to screen investment proposals. Most firms using the NPV rule also use alternative decision criteria. But this observation should not distract from the facts that all the alternatives to the NPV method have some shortcomings and that some have serious weaknesses in assessing the value-creating capacity of a project. We summarizes the properties of the IRR investment evaluation methods. Our final recommendation: when alternative methods provide conflicting signals, the value-creating manager should trust the NPV approach.

\section{References}

[1] Christian Gollier, Expected net present value, expected net future value, and the Ramsey rule, Journal of Environmental Economics and Management, 59 (2010) 2142-2148.

[2] Tsu-Pang Hsieh, Chung-Yuan Dye, Liang-Yuh Ouyang, Determining optimal lot size for a two-warehouse system with deterioration and shortages using net present value, European Journal of Operational Research, 191 (2008) 182-192.

[3] Mario Rese, Markus Karger, Wolf-Christian Strotmann, The dynamics of Industrial Product Service Systems (IPS2) - using the Net Present Value Approach and Real Options Approach to improve life cycle management, CIRP Journal of Manufacturing Science and Technology, 1(2009) $279-286$.

[4] Feroz Kabir Kazia, Joshua A. Fortmana, Robert P. Anexa, David D. Hsub, Andy Aden, Abhijit Dutta, Geetha Kothandaraman, Techno-economic comparison of process technologies for biochemical ethanol production from corn stove, Fuel, 189 (2010) S20 - S28.

[5] Ming Yang, William Blyth, Richard Bradley, Derek Bunn, Charlie Clarke, Tom Wilson, Evaluating the power investment options with uncertainty in climate policy, Energy Economics, $30(2008) 1933-1950$.

[6] Bartł omiej Igliń ski, Roman Buczkowski, Anna Igliń ska, Marcin Cichosz, Grzegorz Piechota, Wojciech Kujawski, Agricultural bio-gas plants in Poland: Investment process, economical and environmental aspects, bio-gas potential, Renewable and Sustainable Energy Reviews, 16 (2012) $4890-4900$.

[7] Kaveh Khalili Damghani, Soheil Sadi-Nezhad, M.B. Aryanezhad, A modular Decision Support System for optimum investment selection in presence of uncertainty: Combination of fuzzy mathematical programming and fuzzy rule based system, Expert Systems with Applications, 38 (2011) 824-834.

[8] Peter Miller, Ted O'Leary, Mediating instruments and making markets: Capital budgeting, science and the economy, Accounting, Organizations and Society, 32 (2007) 701-734.

[9] Ethan Ilzetzki, Enrique G. Mendoza, Carlos A. Végh, How big (small?) are fiscal multipliers? Journal of Monetary Economics, 60 (2013) 239-254.

[10] Matt Croucher, Potential problems and limitations of energy conservation and energy efficiency, Energy Policy, 39(2011) 5795-5799. 